\title{
И.В. Смирнов
}

\section{ЭВОЛЮЦИОННЫЕ ПРОБЛЕМЫ ИЗМЕНЕНИЯ ХАРАКТЕРА ТРУДОВОЙ ДЕЯТЕЛЬНОСТИ}

\begin{abstract}
В данной статье рассматривается эволючия характера труда с течением времени с точки зрения двух наиболее распространенных теорий: пяти способов производства и информационного общества. Анализируются актуальность этих концепций и возможность применения их достижений на современном этапе развития социальнотрудовых отношений. Делается вывод о проникновении в современное общество категории отчуждения труда, влекущей за собой череду негативных последствий психологического и экономического характера как для отдельного предприятия, так $u$ для всего общества в иелом. Проблема отчуждения, ранее распространяемая только на труд рабочих, в информационном обществе охватывает и креативньй класс общества, серьезно сказываясь на его потенциале. При этом проблема отчуждения в современной науке рассмотрена очень слабо. В связи с этим делается ряд предположений о возможных направлениях решения проблемы.

Ключевые слова: экономика труда, эволюция труда, отчуждение труда, информационное общество, гуманизация труда.
\end{abstract}

В современной науке о труде по-прежнему крайне актуальной и спорной остается тема эволюции труда в историческом процессе развития общества. Несмотря на значительный прогресс в этом вопросе, состояние рынка труда, эффективность трудовой деятельности, социальное положение рабочих и прочие показатели благосостояния общества, как и раньше остаются далекими от идеала и в нашей стране, и в большинстве зарубежных государств. В данной статье мы попробуем разобраться в современных подходах к проблемам труда и выявить причины столь неэффективного взаимодействия науки и общества в этом вопросе.

В научной литературе встречается множество подходов к проблеме эволюции трудовой деятельности, однако в целом они составляют пояс двух фундаментальных теорий общественного развития.

Первая из них - это «теория 5 способов производства», распространенная и догматизированная в советской науке. По сути, она представляет собой несколько переработанный вариант теории общественно-экономических формаций К. Маркса. Согласно ей любое общество проходит 5 последовательных этапов эволюции способов производства и производительных сил (а следом за ними, и общественных отношений): первобытно-общинный, рабовладельческий, феодальный, капиталистический и в итоге коммунистический [1. С. 146].

Первобытно-общинный строй характеризуется общей деятельностью на благо общины, с централизованным распределением, благодаря чему в науке присутствует даже такое определение этого этапа, как первобытный коммунизм. Однако с появлением орудий труда, а затем излишков производства в 
обществе возникает неравенство. Как результат, начиная с рабовладельческого этапа, производство, трудовая деятельность осуществляются эксплуатируемым большинством в пользу господствующего социального меньшинства, присваивающего большую часть общественного богатства. В результате возникает диалектика между двумя социальными классами, борьба между которыми ведет к общественному прогрессу, осуществляемому через резкие переходы (социальные революции). По достижению коммунизма же общество возвращается к труду на общее благо, где добавочный продукт распределяется на благо всех, а не становится достоянием отдельных лиц. Каждый человек имеет возможность получения необходимых для жизни ресурсов «по потребностям», осуществляя трудовую деятельность «по способностям».

Если на ранних этапах исторического развития негативные стороны трудовой эксплуатации были очевидны, то в капиталистическом обществе, по мнению марксистов, создается видимость справедливого обмена труда на заработную плату. На самом деле рабочий получает лишь мизерную часть добавочного продукта, достаточную лишь для поддержания в нем возможности трудиться [2. С. 44]. При этом работодатель стремится выжать из рабочего весь его потенциал.

Естественно, что современная промышленность, организация труда и социальная политика достигли значительного прогресса со времен работ Маркса, обеспечив даже неквалифицированных рабочих достаточно высоким уровнем жизни (безусловно, в данном случае мы подразумеваем развитые страны). Тем не менее риторика марксистов изменений не претерпела - они до сих пор считают рабочий класс угнетенным и единственно достойным играть определяющую роль в развитии общества.

Несмотря на ретроспективность марксистов, ряд их концепций имеет место быть и в современной экономике. Отдельно стоит упомянуть о такой категории, активно используемой марксистами, как «отчуждение». Суть этого явления заключается в том, что трудящийся вследствие особенностей функционирования капиталистической экономики и производства утрачивает связь с продуктом своего труда, а затем и со всем миром в целом, теряя смысл своего существования. Маркс утверждал, что труд, в естественных условиях имеющий значение развития личности, изуродован капиталистической системой. Машинизация труда лишила человека творческой стороны в труде, заменив его монотонными операциями, изничтожающими его личность, а результаты труда присваиваются владельцем средств производства. Трудящийся перестает воспринимать продукт как свой собственный, труд становится для него чуждым и тягостным событием [2. С. 44].

К сожалению, в силу ряда объективных обстоятельств (экономического характера исследований, слабого уровня развития психологической науки) Маркс не смог уделять исследованию отчуждения должного внимания. Более глубоко эту концепцию рассматривали его последователи, в частности, особенных успехов достиг на этом поприще представитель Франкфуртской школы социологии Эрих Фромм. В его работах произошло крайне удачное слияние достижений марксизма, экзистенциализма и психоанализа, позволяющее достаточно полно рассмотреть отчуждение. По мнению Фромма, при капиталистической системе отчуждение - это неизбежная участь любого человека 
[3. С. 230]. Вкупе с естественными для человека экзистенциальными тревогой и отчаянием отчуждение приводит к серьезнейшим психологическим проблемам, вызванным глубокой неудовлетворенностью жизнью. Все это приводит к явлению, названному Фроммом «бегством от свободы»: человек старается сбежать от ответственности за собственную жизнь, передавая ее религии, государству, обществу и даже работодателю (такие объекты, служащие прикрытием от реальности, получили наименование «волшебный помощник»). Как результат, человек теряет свою собственную личность, растворяясь в общественной массе, выполняя то, что от него требует общество, а не собственные желания и позывы, свое несчастье только усугубляя [4]. Именно эти психологические процессы, по мнению автора, в результате привели к распространению всех тоталитарных режимов, и фашизма в частности. Фромм развил идею Маркса о различных проявлениях отчуждения, выделив следующие основные направления [3. С. 231-233]:

Отчуждение от продукта труда. Помимо классического отчуждения от объекта трудовой деятельности, человек теряет связь и с потребляемой продукцией. Изначальная цель удовлетворения потребностей - удовольствие подменяется идеей потребления как цели человеческой жизни. Кроме того, человеку навязывается совершенно ненужная, излишняя продукция. Человек не получает удовольствия от потребления, испытывая постоянный потребительский голод, поддерживаемый рекламой. Помимо этого, реклама, эксплуатируя достижения психологии, возбуждает в человеке чувство собственной неполноценности, усиливая экзистенциальную тревогу и чувство собственной ничтожности [3].

Отчуждение от институцииональной системы. Человек боится институтов, которые сам же создал. Государство, религия, экономическая система и прочие стали настолько огромными и сложными, что человек чувствует себя ничтожным в сравнении с этими бюрократическими машинами. В результате теперь не он использует их для улучшения собственной жизни, а они используются для дополнительной его эксплуатации.

Отчуждение от других людей. Человек рассматривает других людей и отношения с ними, как любой другой элемент купли - продажи, сквозь призму рыночных отношений. Любовь, дружба и другие формы человеческих взаимоотношений потеряли свою естественность, превратившись в форму обмена услугами.

Самоотчуждение - худшая и предельная форма отчуждения. Человек более не рассматривает себя как личность, носителя творческих сил, чувств и стремлений. Он представляет себя набором компетенций, который он должен как можно более выгодно продать: работодателю, обществу, семье и другим участникам общественных отношений. Он становится тем, кем указано, играя общественную роль, будучи не личностью, но одним из тысяч таких же «актеров».

Безусловно, работы Фромма имеют огромное значение даже для современной трудовой системы. В первую очередь они важны тем, что отчуждение существенно дополнилось психологическими, экономическими и административными характеристиками, значимо расширив это понятие от технической стороны, на которой концентрировался Маркс. Помимо этого, в своих рабо- 
тах Фромм распространяет влияние отчуждения на все социальные категории общества: от люмпен-пролетариата до капиталистов, просто отчуждение меняет свою форму и имеет разные последствия. Особенно ценны доводы Фромма тем, что они актуальны и в современной, информационной экономике.

Какой выход видят сторонники левых идей из сложившейся ситуации? С точки зрения марксистов, единственным выходом из этой череды страданий и угнетения для подавляющей массы населения является переход к коммунистическому либо социалистическому обществу, осуществленный путем пролетарской революции. Базисом этих обществ должно быть разумное потребление, централизованное и справедливое распределение благ, а также труд, основанный на принципах справедливой ротации и способностей. Технический прогресс, социальная помощь и другие меры, улучшающие условия труда рабочего в капиталистическом обществе, не являются условиями освобождения человека. Виновной в человеческом несчастье считается сама капиталистическая система.

Данная ситуация хорошо описана в статье американского журналиста Г. Сводоса «Миф о счастливом рабочем», опубликованной в 1966 г. в журнале «Иностранная литература»: «Грубая правда заключается в том, что работа на заводе отупляет людей. Она отупляет любого, кто мечтает совершить в жизни что-нибудь стоящее, и это пора наконец открыто признать. Для иммигранта, который надрывался в полутемных, мерзких, кишащих паразитами потогонных мастерских, работа была менее отупляющей, чем для нашего окончившего среднюю школу современника, хотя он работает при лампах дневного света, на машинах с кнопочным управлением. Ибо рабочийиммигрант, даже если он и не мечтал о социализме, верил, что долгими часами работы он купит себе свободу. А промышленный рабочий пятидесятых годов рассчитывает лишь, что долгие часы труда помогут ему купить мебель и тряпки и хоть отчасти расплатиться с долгами». По мнению автора, рабочий, даже высокотехнологического производства, никогда не сравняется по уровню жизни со средним классом (вопреки всеобщему мнению). Этого не произойдет именно в силу характера труда рабочего, приводящего к его умственной и психологической деградации [5]. Современный опыт доказывает правоту таких суждений: стремление к материальной выгоде по-прежнему сильно превосходит прочие потребности у рабочих, несмотря на некоторые положительные тенденции [6. С. 100].

К сожалению, исторический опыт продемонстрировал если не утопичность социалистической идеи, то ее несвоевременность и труднодостижимость. Имея благие цели, плановая экономика все же оказалась не способна обеспечить материальные потребности людей, избавиться от денежной зависимости и исключить появление отчуждения, часто лишь обостряя экономические и социальные проблемы.

В противовес марксистскому подходу к эволюции характера труда в зарубежной науке в 60-х гг. возникла теория информационного (постиндустриального) общества, предложившая свой взгляд на этот вопрос. Она выделяет иные этапы экономического развития общества и их основные характеристики (таблица). 
Этапы общественного развития и их основные характеристики с точки зрения теории информационного общества

\begin{tabular}{l|l|l|l}
\hline $\begin{array}{c}\text { Основные характери- } \\
\text { стики }\end{array}$ & $\begin{array}{c}\text { Доиндустриальное об- } \\
\text { щество }\end{array}$ & \multicolumn{1}{|c|}{$\begin{array}{c}\text { Индустриальное } \\
\text { общество }\end{array}$} & $\begin{array}{c}\text { Постиндустриальное } \\
\text { общество }\end{array}$ \\
\hline $\begin{array}{l}\text { Главная отрасль } \\
\text { Основной экономиче- } \\
\text { ский ресурс }\end{array}$ & Сельское хозяйство & Промышленность & Услуги \\
\hline $\begin{array}{l}\text { Главная социальная } \\
\text { группа }\end{array}$ & Землевладельцы & Капитал & Информация \\
\hline Содержание труда & Ручной труд & $\begin{array}{l}\text { Однообразные ма- } \\
\text { шинные операции }\end{array}$ & $\begin{array}{l}\text { Управление, интел- } \\
\text { лектуальная и твор- } \\
\text { ческая деятельность }\end{array}$ \\
\hline
\end{tabular}

Смена парадигм в данной системе осуществляется за счет научнотехнических революций (а не социальных), менявших способ производства, а следовательно, и характер трудовой деятельности.

Отрицательное влияние характера труда индустриального общества не подвергается сомнению сторонниками этой концепции. Это следует из особенностей труда того времени: наличия у рабочих лишь минимально необходимых технических знаний, унификации трудовой деятельности (однообразие), привития покорности, борьбы со всеми формами активности и инициативности [7. С. 43].

В то же время современная трудовая деятельность характеризуется:

- высоким профессионализмом;

- $\quad$ наличием в деятельности творческих элементов;

- обязательным наличием экономических знаний и представлений;

- управленческой подготовкой;

- целеустремленностью и добросовестностью, трудолюбием и лояльностью к коллективу;

- психологической устойчивостью;

- человечностью и стремлением к личностному росту.

Достижения науки, с помощью которых произошла автоматизация и компьютеризация большинства трудовых процессов, привели, по мнению сторонников данной теории, к некоторому «освобождению» трудящихся от механистической стороны труда, дав больший простор самореализации в творческой и научной деятельности, избавив человека от психологических и социальных проблем, характерных для индустриального общества. В том числе от отчуждения, которое не может быть свойственно интеллектуальной и творческой деятельности.

Однако некоторые современные авторы не согласны с данной позицией. По их мнению, интеллектуальность труда в условиях существующих социально-трудовых отношений только усугубляет психологические проблемы трудящихся. Работодатели заметили, что заработная плата более не способна поддержать в работниках необходимый энтузиазм. По большому счету, она играла лишь роль якоря, удерживая работника на его месте. Соответственно, они были «вынуждены» сделать процесс труда интересным. Это, в свою очередь, привело к тому, что работник стал посвящать своей работе больше времени, делая ее своим хобби. Эксплуатация стала едва ли не круглосуточной, так как работник не прекращает думать о работе даже в кругу семьи. При 
этом отчуждение продукта никуда не исчезло. Более того, оно ужесточилось вследствие более высокой ценности творческого и интеллектуального труда для человеческой личности [8. С. 34-38]. Передавая результаты своей работы, дизайнер, программист или аналитик по-прежнему теряет с ними связь. При этом, в отличие от рабочего, его труд содержит большую долю собственной энергии и морального вклада в силу творческого характера. Нередко он вообще не видит в своей работе смысла, не имея материальной формы выражения своей деятельности. Кроме того, делегирование полномочий и увеличение количества управляющих должностей привели к усилению ответственности и росту давления со стороны внешней среды: коллег, начальства, рынка (с жесточайшей конкуренцией, не свойственной даже индустриальному обществу). Как следствие всего этого, экзистенциальные тревога и неуверенность, потеря смысла существования довлеют над человеком с новой силой, заставляя искать новые пути бегства от своей свободы и самовыражения: физические и интеллектуальные зависимости, склонность к авторитаризму, снижение требований к себе - далеко не полный список проблем, порожденных современным общественным устройством.

Интересен тот факт, что данные о сохранении негативной тенденции в удовлетворенности жизнью в странах с информационной экономикой можно подтвердить статистически: первые пять мест во всемирном индексе счастья занимают Коста-Рика, Вьетнам, Колумбия, Белиз и Сальвадор - страны с преимущественно сельскохозяйственной экономикой, причем с низким уровнем ее технического оснащения. Ближайшее государство, характеризуемое как постиндустриальное - Израиль, занимает лишь 15-е место, далее Новая Зеландия и Норвегия: 28-е и 29-е [9]. Есть и другая статистика: такие странылокомотивы постиндустриальной экономики, известные своей высочайшей культурой труда, как Южная Корея и Япония, занимают 3-е и 18-е место по частоте самоубийств на душу населения, значительно превосходя по этому показателю, к примеру, Центральноафриканскую Республику и Габон [10]. Важно отметить, что самоубийство с точки зрения философии экзистенциализма является альтернативным способом избавления от драматизма и бессмысленности жизни. Смерть выступает как некая альтернатива творческой самореализации личности в случае, когда последнюю невозможно реализовать.

Из этой информации следует вывод - интеллектуального и творческого самовыражения в условиях постиндустриального общества недостаточно для самореализации личности и достижения человеческого счастья. Новая система организации труда внесла значительные улучшения в условия труда: труд стал более гуманным, при его организации стали учитываться человеческие потребности и способности, он стал одним из инструментов саморазвития [11. С. 135]. Тем не менее приложенных усилий явно не достаточно. Гонка за производительностью, прибылью и другими ценностями капиталистического общества может отрицательно сказаться на душевно-психологическом состоянии человека, став причиной серьезнейших общественных проблем.

Во избежание общественных потрясений и для продолжения общественного прогресса современной наукой о труде, а также практиками из отделов персонала предприятий необходимо актуализировать работу по гуманизации 
труда постиндустриального общества, не успокаиваясь избавлением трудящегося от физической нагрузки. Нашему обществу жизненно необходимо продолжать поиски способов трудовой реализации, которые не будут вызывать отвержения со стороны человеческой натуры и при этом не приведут к снижению общественной производительности.

\section{Литература}

1. Ефимов В.И., Мраморнова О.В. Эволюция содержания труда в процессе экономического развития общества // Вестн. Саратов. гос. техн. ун-та. 2009. № 1. С. 145-153.

2. Экономическо-философские рукописи 1844 года // Маркс К., Энгельс Ф. Собр. соч. T. 42. C. 41-174.

3. Фромм Э. Человек одинок // Иностранная литература. 1966. № 1. С. 230-233.

4. Фромм Э. Бегство от свободы. М.: АСТ, 2009. 288 с.

5. Сводос Г. Миф о счастливом рабочем // Иностранная литература. 1966. № 1. С. 234-236.

6. Шиняева О.В., Артемьева T.B. Отношение рабочих промышленных предприятий к труду // Изв. вузов. Поволжский регион. Общественные науки. 2013. № 3 (27). С. 100-112.

7. Горбунова О.Н., Горбунова Ю.И., Шестакова Ю.В. Эволюция требований, предъявляемых к специалисту на рынке труда в процессе общественного прогресса // Наука и мир. 2014. № 3(7). C. 42-45.

8. Григорьева Я.В. Трансформация труда в современном обществе. Новые формы угнетения // Вест. Перм. нац. иссл. политехн. ун-та. Культура. История. Философия. Право. 2012. № 5. C. $34-39$.

9. The Happy Planet Index: 2012 Report. London: New economics foundation, 2012. 27 p.

10. Preventing suicide: a global imperative. Geneva: World health organization, 2014. 102 p.

11. Герман M.B. Профессиональный уровень индивида, его изменения и условия формирования в контексте происходящих трансформационных процессов в обществе // Вестн. Том. гос. ун-та. 2007. № 298. С. 135-138.

I.V. Smirnov. Department of System Management and Economics of Enterpreneurship, Tomsk State University, Tomsk, Russia. E-mail: Ilia.S91@yandex.ru

\section{EVOLUTIONARY CHANGE IN THE NATURE OF THE PROBLEM OF EMPLOYMENT.}

Keywords: labor economics, the evolution of labor, the alienation of labor, information society, humanization of work.

This article examines the evolution of the nature of work in course of time in terms of the two most common theories: the five modes of production and the information society. The theory of the five modes of production was created by Karl Marx, and was widespread in the economics of the USSR and other countries of the socialist bloc. In turn, pre-Communist formations are accompanied by a suppression of the main mass of people to maximize the welfare of minorities. It is in this supporters of the Marxist theory sees the main source of most of the problems of modern society. In contrast to this approach is the theory of the information society. Its supporters see scientific and technical progress as the main source of positive changes of social development and progress of labor relations. From their point of view, technological developments will contribute to the gradual improvement of working conditions, professional development and quality of life of employees.

The history has shown that closer to the truth turned out to be supporters of the theory of the information society - labor in developed countries gains predicted nature more and more, while the Marxists apocalyptic predictions have not been fulfilled. Nevertheless, the problems of capitalist society, which were pointed at by the supporters of socialism, persist, and they are seriously affecting the social development.

Resolution of these problems is an important task for researchers of different industries - from mechanical engineering to sociology. At the same time, ignoring them, amid growing inequality and uneven economic development of the world can lead to serious social, economic, psychological and political consequences, up to growth of revolutionary sentiment. 


\section{References}

1. Efimov V.I., Mramornova O.V., Evoluziy soderzaniy truda v prozesse economicheskogo razvitiy obsestva [The evolution of the content of labor in the process of economic development of society]. Vestnik Saratovskogo gosudarstvennogo tehnicheskogo universiteta, 2009, no.1, pp. 145-153.

2. Marx K., Engels F. Sobranie sochineney [Collected works]. T.42. Economico-filosofskie rukopisi 1844 goda, pp. 44-174.

3. Fromm E. Chelovek odinok [Man for himself]. Zarubeznay literatura, 1966, no.1, pp. 230-233.

4. Fromm E. Begstvo ot svobody [Escape from Freedom]. Moscow, AST, 2009. 288 p. Zarubeznay literatura, 1966, no.1, pp. 234-236.

5. Svodos G. Mif o scastlivom rabochem [The myth of the happy workers].

6. Shinyeva O.V., Artemeyeva T.V. Otnoshenye rabochih promislenneh predpriytie k trudu [The ratio of industrial workers to work]. Izvestiy viscih ucebnih zavedeniy. Povolskiy region. Obsestvennye nauki. 2013, no. 3 (27), pp. 100-112.

7. Gorbunova O.N., Gorbunova U.I., Shestakova U.V. Evoluziy trebovaniy, predyvlyemih k specialistu na rynke truda $\mathrm{v}$ prozesse obshestvennogo progressa [Evolution of requirements to a specialist in the labor market in the course of social progress]. Nauka I mir, 2014, no. 3(7), pp.42-45.

8. Grigorieva Y.V. Transformaciy truda v sovremennom obshestve. Novie formy ugneteniy [Transformation of labor in modern society. New forms of oppression]. Vestnik Permskogo nazionalnogo issledovatelskogo politihnicheskogo universiteta. Kultura. Istoria. Filosofia. Pravo, 2012, no.5, pp. 34-39.

9. The Happy Planet Index: 2012 Report. London: New economics foundation. 2012. 27 p.

10. Preventing suicide: a global imperative. Geneva: World health organization; 2014. $102 \mathrm{p}$.

11. German M.V. Proffesionalnyi uroven individa, ego ismenenia i uslovia formirovania $\mathrm{v}$ kontekste proishodysih transformacionnyh processov $\mathrm{v}$ obshestve [The professional level of the individual, its changes and formation conditions in the context of the ongoing transformation processes in the society]. Vestnik Tomskogo gosudarstvennogo universiteta, 2007, no. 298. pp. 135-138. 